\title{
Rerouting the Pathway for the Biosynthesis of the Side Ring System of Nosiheptide: The Roles of Nosl, NosJ, and NosK
}

Edward D. Badding, ${ }^{\ddagger}$ Tyler L. Grove, ${ }^{\ddagger \dagger}$ Lauren K. Gadsby, ${ }^{\S}$ Joseph W. LaMattina, ${ }^{\ddagger}$ Amie K. Boal, ${ }^{*}, \S_{\circledast}$ and Squire J. Booker*, ${ }^{*}, \|_{\odot}$

${ }^{\ddagger}$ The Department of Chemistry, ${ }^{\S}$ The Department of Biochemistry and Molecular Biology, and ${ }^{\|}$The Howard Hughes Medical Institute, The Pennsylvania State University, University Park, Pennsylvania 16802, United States

Supporting Information

ABSTRACT: Nosiheptide (NOS) is a highly modified thiopeptide antibiotic that displays formidable in vitro activity against a variety of Gram-positive bacteria. In addition to a central hydroxypyridine ring, NOS contains several other modifications, including multiple thiazole rings, dehydro-amino acids, and a 3,4-dimethylindolic acid (DMIA) moiety. The DMIA moiety is required for NOS efficacy and is synthesized from L-tryptophan in a series of reactions that have not been fully elucidated. Herein, we describe the role of NosJ, the product of an unannotated gene in the biosynthetic operon for NOS, as an acyl carrier protein that delivers 3-methylindolic acid (MIA) to NosK. We also reassign the role of NosI as the enzyme responsible for catalyzing the ATP-dependent activation of MIA and MIA's attachment to the phosphopantetheine moiety of NosJ. Lastly, NosK catalyzes the transfer of the MIA group from NosJMIA to a conserved serine residue (Ser102) on NosK. The X-ray crystal structure of NosK, solved to $2.3 \AA$ resolution, reveals that the protein is an $\alpha / \beta$-fold hydrolase. Ser102 interacts with Glu210 and His 234 to form a catalytic triad located at the bottom of an open cleft that is large enough to accommodate the thiopeptide framework.

\section{INTRODUCTION}

Nosiheptide (NOS) is one of the oldest known thiazolyl peptide (thiopeptide) natural products and is commonly used as a feed additive to promote growth in pigs and poultry. ${ }^{1-3}$ It displays formidable activity against a variety of Gram-positive bacteria of clinical relevance, including methicillin-resistant Staphylococcus aureus, penicillin-resistant Streptococcus pneumoniae, and vancomycin-resistant enterococci. ${ }^{1}$ Its mode of action involves binding to the bacterial ribosome and inhibiting translation by blocking translocation along the mRNA transcript. $^{2-4}$ Although NOS exhibits impressive in vitro activity, its use in humans as a therapeutic agent is limited by its low solubility and poor pharmacokinetic properties. As a result, efforts are underway to modify this natural product, and others similar to it, via synthetic, biosynthetic, and semisynthetic means to transform it into a useful antibacterial agent. $^{5,6}$

NOS is a highly modified sulfur-rich bicyclic peptide that features a central hydroxypyridine ring, from which a number of thiazole rings and dehydro-amino acids emanate (Figure 1). In addition to these core features, NOS carries a distinguishing 3,4-dimethylindolic acid (DMIA) moiety, which is common to the $e$ series thiopeptides. The DMIA moiety is appended to the thiopeptide framework via ester and thioester linkages to the side chains of specific glutamyl and cysteinyl residues, respectively, of a precursor peptide, generating a side ring system. ${ }^{7}$ The NOS biosynthetic gene cluster from Streptomyces actuosus was identified by Liu and co-workers, and is composed of 16 genes, which are designated nosA-nosP (Figure $2 \mathrm{~A}$ ). ${ }^{8}$ The thiopeptide framework is ribosomally synthesized as a precursor peptide, which is encoded by the nos $M$ gene. NosM is a peptide of 50 amino acids (aa), in which residues 1-37 constitute a leader peptide that is important in recognition by several enzymes that catalyze the extensive post-translational modifications. The remaining $13 \mathrm{C}$-terminal aa compose a structural peptide of sequence SCTTCECCCSCSS. NosD, E, F, G, H, and O are postulated to be involved in generation of the thiopeptide framework, given that homologues are found in operons for the biosyntheses of similar thiopeptides in other organisms. ${ }^{3}$ NosG and NosH function as a complex to catalyze cyclodehydration, whereas NosF is a dehydrogenase. Together, they catalyze formation of the thiazole rings of NOS. NosE and NosD work sequentially to give rise to the dehydro-amino acids. NosO, which shares $\sim 30 \%$ sequence identity with $\mathrm{TbtD}$, shown to generate the nitrogen-containing six-membered heterocycle in thiomuracin, ${ }^{9,10}$ most likely generates the analogous heterocycle in NOS (Figure 1).

Received: February 12, 2017

Published: March 27, 2017 


\section{core macrocycle}

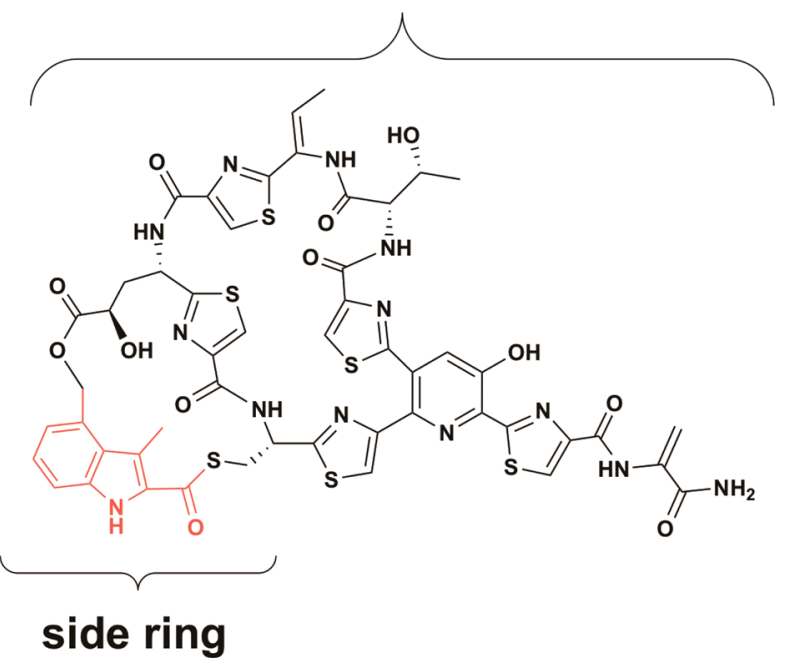

Figure 1. Structure of nosiheptide featuring the dimethylindolic acid (DMIA) moiety (red).

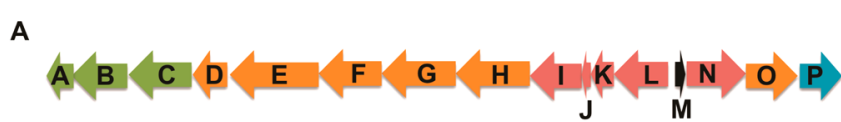

B

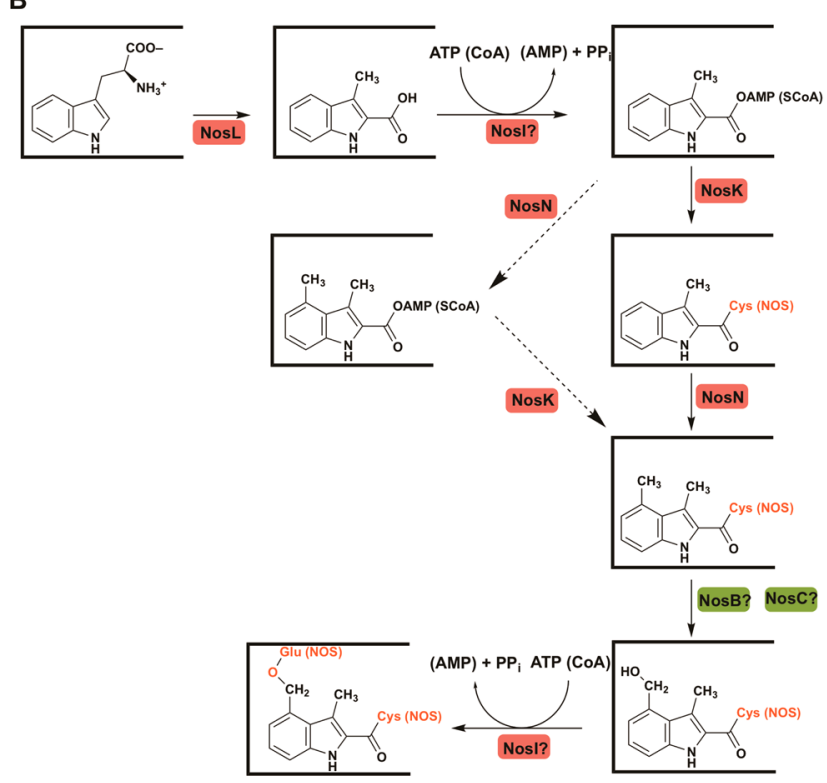

Figure 2. (A) nos operon. (B) Postulated pathway for formation of the DMIA moiety of NOS.

The encoded proteins, NosA, B, and C, are tailoring enzymes. NosA generates the $\mathrm{C}$-terminal amide group of the thiopeptide, $^{11}$ whereas NosB and NosC, annotated as cytochrome $\mathrm{P}_{450}$-like enzymes, hydroxylate the $\gamma$-carbon of the glutamyl residue, and $\mathrm{C} 3$ of the nitrogen-containing heterocycle, respectively. ${ }^{12}$ Lastly, NosI, J, K, L, and $\mathrm{N}$ are involved in the biosynthesis and attachment of the DMIA moiety of NOS.

A scheme for formation and attachment of the DMIA moiety of NOS has been advanced by Liu and colleagues, and is shown in Figure $2 \mathrm{~B} .^{8}$ It is well established that NosL catalyzes the initial step in the pathway, which is a radical-dependent conversion of tryptophan (Trp) to 3-methylindolic acid
(MIA). ${ }^{13}$ MIA was then suggested to be converted to its AMP or CoA derivative by an undesignated enzyme, after which, NosN appends a methyl group to C4 of MIA to give DMIA. NosK, annotated as a member of the $\alpha / \beta$-fold hydrolase family, was predicted to attach DMIA to the appropriate cysteinyl residue of the thiopeptide framework, and an undesignated protein (most likely NosB or NosC) was predicted to hydroxylate C4 of DMIA. Lastly, NosI, annotated as an AMP-dependent acyl-CoA synthetase/ligase, was predicted to activate the glutamyl residue in the structural peptide by adenylation and catalyze the last step in formation of the minor macrocycle by facilitating attack of the $\mathrm{C} 4$ hydroxyl group onto the activated glutamyl residue to generate the ester linkage. ${ }^{13}$ The authors also noted that NosN might not act directly on MIA, but rather after MIA has been attached to the cysteinyl residue of the NOS thiopeptide framework (Figure 2B). Though the postulated pathway for NOS biosynthesis is enticing, certain issues stand out. For example, only two cytochrome $\mathrm{P}_{450}$ enzymes are encoded in the nos operon (NosB and $\mathrm{Nos} C$ ) and both have assigned functions (see above). ${ }^{12}$ Therefore, no reasonable candidates to hydroxylate C4 of DMIA are encoded in the nos operon. Moreover, although Floss and colleagues showed that DMIA, administered externally to growing $S$. actuosus, was incorporated into intact NOS, C4-hydroxymethyl-MIA was not. ${ }^{14}$

Our interest in nosiheptide biosynthesis stems from the predicted activity of NosN, which has been suggested to methylate $\mathrm{C} 4$ of an MIA moiety during nosiheptide biosynthesis. NosN is annotated as a radical $S$-adenosylmethionine (SAM) enzyme, meaning that it uses the oxidative power of a $5^{\prime}$-deoxyadenosyl $5^{\prime}$-radical $\left(5^{\prime}\right.$-dA. $)$ to initiate radical-based transformations. The $5^{\prime}$-dA . derives from SAM via a reductive fragmentation reaction that requires the participation of a $[4 \mathrm{Fe}-4 \mathrm{~S}]$ cluster, a metallocofactor that is common among all enzymes of the radical SAM (RS) superfamily. One of the emerging areas in RS enzymology is the methylation of unactivated carbon or phosphinate phosphorus atoms. Several strategies have become apparent, and the choice of which to use appears to depend on the structure of the substrate and the hybridization of the carbon atom ( $s p^{2}$ - or $s p^{3}$-hybridized) undergoing methylation. NosN is a member of Class C RS methylases, which are understudied, because they tend to operate on complex natural products. ${ }^{15,16}$ The work described herein details our efforts to identify the substrate for NosN, which has led us to revise the pathway by which DMIA of NOS is biosynthesized.

\section{RESULTS}

Characterization of NosJ. In the original description of proteins encoded by the nos operon for NOS biosynthesis, NosJ was not attributed a function. The nosJ open reading frame (orf), however, encodes for a protein of 79 aa with a molecular mass $\left(M_{\mathrm{r}}\right)$ of $8849 \mathrm{Da}$, which is similar to the $M_{\mathrm{r}}$ of an acyl carrier protein (ACP). ${ }^{17,18}$ For example, Escherichia coli acyl carrier protein, AcpP, is composed of 78 aa and has an $M_{r}$ of $8640 \mathrm{Da}$. AcpP does not contain any cysteinyl residues, but the protein is post-translationally modified at Ser-37 with a $4^{\prime}$ phosphopantetheine group, which terminates in a sulfur atom. In AcpP, Ser-37 is found in a DS ${ }^{37}$ LDTV motif, present in NosJ as DSLETV. ${ }^{17,18}$ A BLAST analysis of NosJ using default parameters in UniProt yielded best matches with several other proteins from Streptomyces, including an uncharacterized protein from Streptomyces afghaniensis 772; the C-terminal 

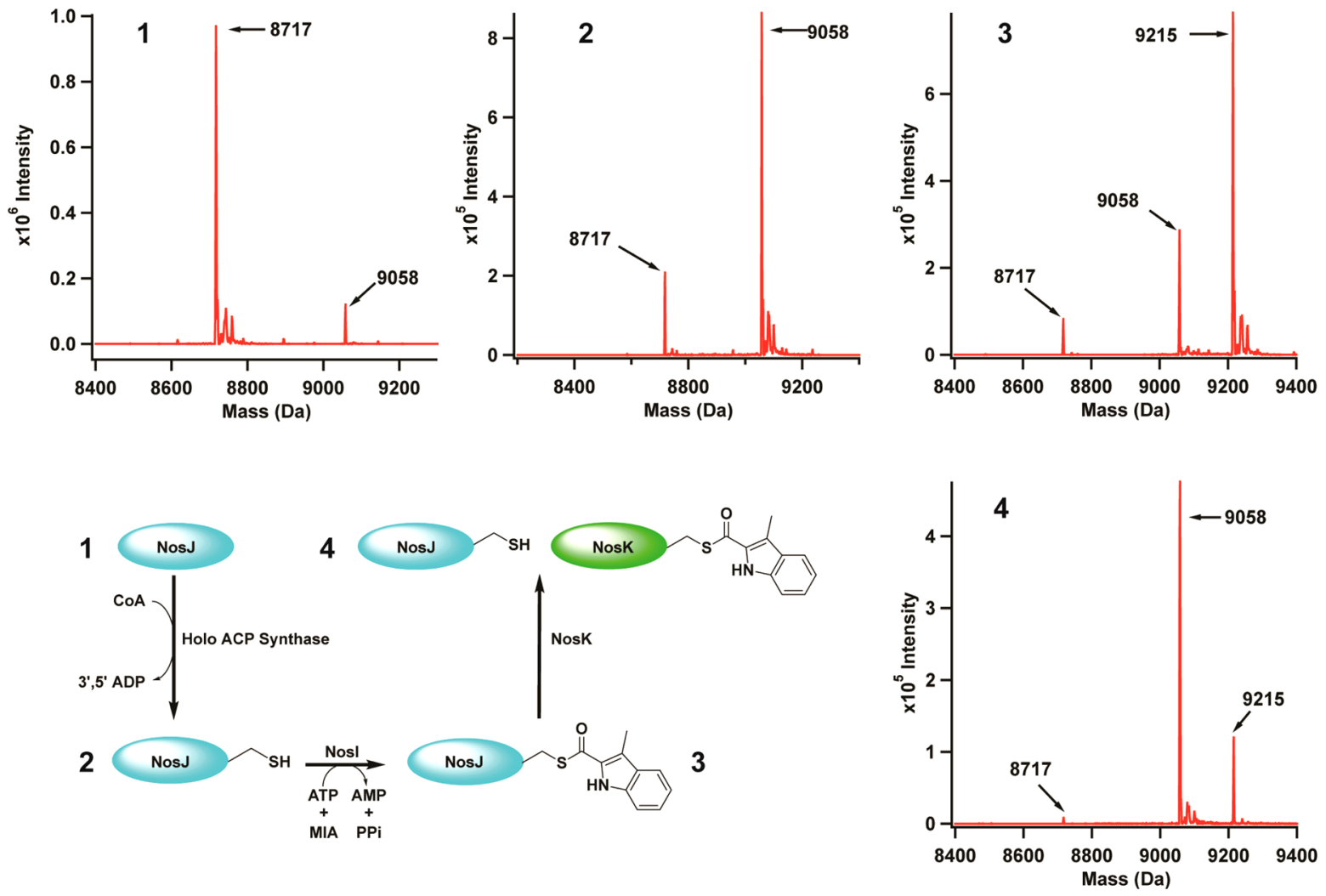

Figure 3. Characterization of NosJ and NosK. Panel 1 shows as-purified NosJ (theoretical mass is $8717.63 \mathrm{Da}$ ). Panel 2 displays the mass shift corresponding to the transfer of $4^{\prime}$-phosphopantetheine to NosJ to produce holo NosJ (theoretical mass is 9057.96 Da). Panel 3 shows the NosIdependent transfer of MIA to NosJ to produce MIA-holo NosJ (theoretical mass is $9215.13 \mathrm{Da}$ ). Finally, upon incubation with NosK, MIA-holo NosJ is reverted back to holo NosJ due to MIA transfer to NosK (Panel 4). The proposed reaction scheme is shown at bottom left.

region of NocK from Nocardia Sp., which is involved in nocathiacin biosynthesis, another thiopeptide antibiotic; TsrI from Streptomyces laurentii, which is involved in thiostrepton biosynthesis; and SioP from Streptomyces sioyaensis, which is involved in siomycin biosynthesis. All of these organisms produce thiopeptide antibiotics that contain side ring systems containing appendages derived from tryptophan, either DMIA (NOS and nocathiacin) or a quinaldic acid moiety (thiostrepton and siomycin)., ${ }^{2,3}$

To determine whether NosJ is an ACP, the protein was overproduced heterologously in E. coli and then purified using procedures similar to those used to isolate E. coli ACP. ${ }^{19,20}$ The protein is $>95 \%$ pure after anion-exchange chromatography using DE-52 resin and gel-filtration chromatography using a Sephacryl S-200 HR 26/60 prepacked column (Figure S1). Analysis of the protein by electrospray-ionization mass spectrometry in positive mode (ESI ${ }^{+}-\mathrm{MS}$ ) shows that it exhibits an $M_{\mathrm{r}}$ of $8717 \mathrm{Da}$, which is consistent with the theoretical $M_{\mathrm{r}}$ $(8717.63 \mathrm{Da})$ after accounting for removal of the N-terminal methionine (Figure 3, panel 1). A small ( $\sim 10 \%)$ portion of NosJ displays a molecular mass of $9048 \mathrm{Da}$ (theoretical mass is $9057.96 \mathrm{Da}$ ), which is consistent with the addition of a $4^{\prime}$ phosphopantheine group (340.34 Da) to the protein during its overproduction in E. coli. To generate a larger fraction of the phosphopantetheinylated form of NosJ (i.e., holo NosJ), the protein was incubated for $30 \mathrm{~min}$ at room temperature with $E$. coli holo ACP synthase, which catalyzes the transfer of the $4^{\prime}$ phosphopantetheine group from coenzyme-A to the target seryl residue to afford holo ACP. ${ }^{18,21}$ As shown in panel 2 of Figure 3, the peak at $M_{\mathrm{r}} 8717 \mathrm{Da}$ decreases in intensity, whereas the peak at $M_{\mathrm{r}} 9058 \mathrm{Da}$ increases in intensity. The observed mass of NosJ and its capacity to be modified with a phosphopantetheine prosthetic group, both in E. coli and as a purified protein, indicate that NosJ is an ACP.

Characterization of Nosl. ACPs typically function as molecular carriers. In fatty acid biosynthesis, they serve as the template upon which fatty acyl chains are elongated. ${ }^{22}$ In nonribosomal peptide synthetases (NRPSs) and polyketide synthetases (PKSs), ACPs exist as carrier or thiolation domains (TDs). ${ }^{23}$ In PKSs, acyl-CoAs existing as primary metabolites are attached to TDs via transthioesterification reactions. In NRPSs, however, amino acids and other metabolites that do not exist naturally as CoA-thioesters must first be activated in an ATP-dependent fashion to give an intermediate amino acid-adenylate species, which is then used to generate the corresponding TD-amino acid thioester. ${ }^{23}$ In the nos operon, NosI is annotated as requiring ATP (AMP-dependent acyl-CoA synthetase), suggesting that it might be involved in the activation and transfer of MIA to holo NosJ. The nosI gene was therefore cloned such that its product would be produced with an $\mathrm{N}$-terminal hexahistidine $\left(\mathrm{His}_{6}\right)$ tag upon expression to facilitate purification by immobilized metal affinity chromatography (IMAC). The protein was purified to $>90 \%$ homogeneity with a yield of $\sim 30 \mathrm{mg}$ from $30 \mathrm{~g}$ of $E$. coli cell paste (Figure S2). The addition of $5 \mathrm{mM}$ ATP to purification buffers was critical for improving the solubility of the protein.

To assess whether NosI activates MIA, NosI was incubated with $1 \mathrm{mM}$ MIA and $1 \mathrm{mM}$ ATP in HEPES buffer, $\mathrm{pH}$ 7.5, and formation of the MIA-adenylate was assessed at designated times by $\mathrm{ESI}^{+}$-MS (Figure 4A). A burst phase of MIA-AMP 

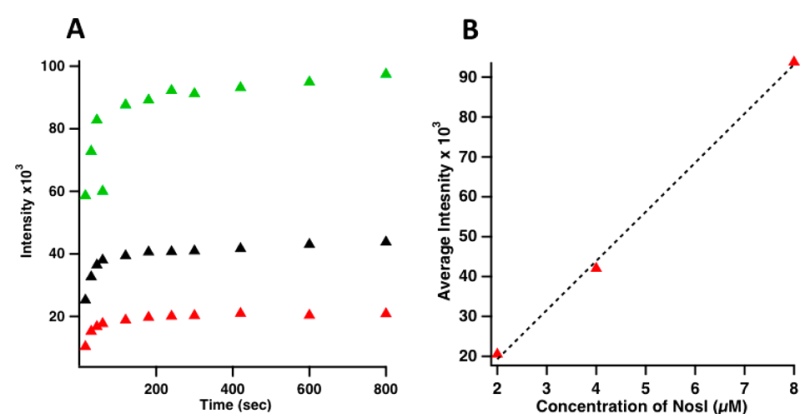

Figure 4. Reaction of NosI with ATP and MIA. ATP (1 mM) and MIA (1 $\mathrm{mM})$ were incubated with 2 (red triangles), 4 (black triangles), $8 \mu \mathrm{M}$ (green triangles) NosI in the absence of NosK for varying lengths of time ( 15 to $800 \mathrm{~s}$ ), and MIA-AMP was measured by LC-MS as a relative integrated response (A). Amplitudes from each of the time courses plotted as a function of NosI concentration show a linear correlation (B). The reactions were conducted in an ice-water bath.

production is observed that is followed by a second phase that is nearly horizontal, suggesting that no additional product formation, or extremely slow product formation, takes place after the initial burst. When the experiment is conducted with varying concentrations of $\operatorname{NosI}(2,4$, or $8 \mu \mathrm{M})$, the amplitudes of the burst phases vary linearly with those concentrations, suggesting that the enzyme catalyzes only one turnover under the conditions described (Figure 4A,B). This behavior suggests that NosI catalyzes both the activation of MIA and its subsequent transfer to some target.

To assess whether holo NosJ is the NosI-dependent acceptor of MIA, NosI was incubated with MIA, ATP, and NosJ, and formation of NosJ-MIA was assessed by HPLC. As shown in Figure 5 (Trace B), apo and holo NosJ migrate at retention

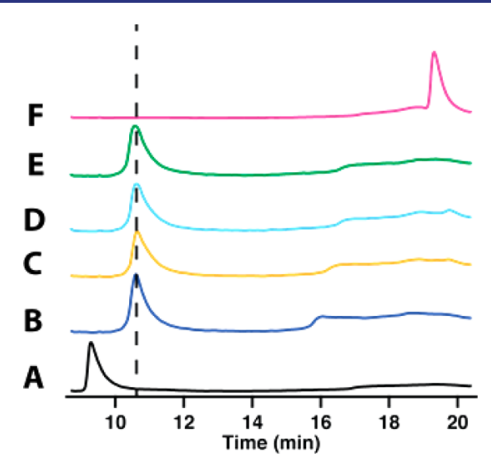

Figure 5. HPLC analysis of holo NosJ upon reaction with ATP, MIA, and NosI. (A) apo NosJ; (B) holo NosJ; (C) holo NosJ + ATP and MIA; (D) holo NosJ + NosI and MIA; (E) holo NosJ + NosI and ATP; and (F) holo NosJ + NosI, MIA, and ATP (complete reaction).

times of 9.8 (black trace) and $10.6 \mathrm{~min}$ (blue trace), respectively, under the conditions described in the Experimental Procedures. When holo NosJ is incubated with NosI, ATP, and MIA, this retention time shifts to $19.3 \mathrm{~min}$, indicating the modification of holo NosJ with MIA (Figure 5, Trace F). Omission of NosI (Trace C), ATP (Trace D), or MIA (Trace E) from the reaction mixture does not result in a shift, in the retention time of holo NosJ, verifying that all of these components are required for modification of holo NosJ. Analysis of NosJ by mass spectrometry after incubating it with NosI, MIA, and ATP revealed it to exhibit an $\mathrm{m} / z$ of 9215
(Figure 3, panel 3), which is consistent with the theoretical mass of MIA-NosJ (9215.13 Da).

Characterization of NosK. In the nos operon, nosJ is adjacent to nosK. In the noc operon, which encodes proteins that are involved in the biosynthesis of nocathiacin, a related thiopeptide antibiotic, the encoded NocJ and NocK proteins are part of the same polypeptide. These observations suggest that NosJ and NosK might have related activities. Therefore, hexahistidine-tagged NosK was purified to homogeneity (100 $\mathrm{mg}$ from $10 \mathrm{~g}$ of $E$. coli cell paste) by IMAC (Figure S3) and characterized. As shown in Figure 6 (blue trace), NosK

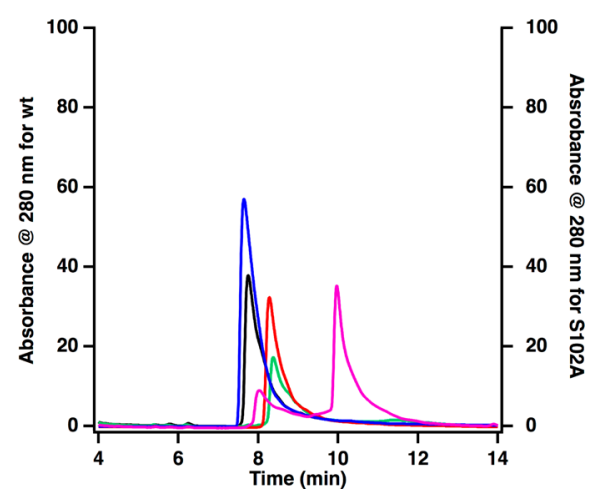

Figure 6. HPLC analysis of the acylation of NosK. NosK, blue; NosK + NosJ, black; NosK + NosJ + NosI, pink; NosK Ser102Ala variant, red; NosK Ser102Ala variant + NosJ + NosI, green.

migrates at a retention time of 7.6 min under the conditions described in the Experimental Procedures. The addition of holo NosJ, MIA, and ATP to NosK results in essentially no change in retention time (Figure 6 black trace). However, the addition of NosI to holo NosJ, MIA, ATP, and NosK results in a change in NosK's retention time from 7.6 to $10 \mathrm{~min}$. When NosK is then digested with trypsin and subjected to mass spectrometry, a peptide is observed ( LIGAS $_{102}$ YLGGPLAHR) that contains $^{2}$ MIA covalently bound to the side-chain of Ser102 (Table S1). In a control reaction, in which ATP is omitted, the same peptide is observed but without the MIA linkage (Table S2).

To confirm the role of Ser102 as an acyl acceptor, the amino acid was changed to alanine and the resulting NosK variant was substituted in the reaction. NosK S102A migrates slightly slower than wild-type NosK, exhibiting a retention time of 8.3 min rather than 7.7 min (Figure 6, red trace). When the NosK S102A variant is incubated with holo NosJ, ATP, MIA, and NosI, no shift in retention time is observed, which is consistent with Ser102 as the intermediate acyl acceptor site. This role for NosK is also consistent with observations reported in Figure 3 (panel 4), wherein the addition of NosK to a reaction containing NosI, NosJ, MIA, and ATP results in the conversion of MIA-NosJ to holo NosJ.

Determination of the X-ray Crystal Structure of NosK. The structure of NosK was solved to $2.3 \AA$ resolution by X-ray crystallography (Figure 7A, PDB accession code 5V7O). The protein exhibits an $\alpha / \beta$ hydrolase fold, as anticipated from initial bioinformatic annotation and is consistent with its experimentally determined acyltransferase function. The site of MIA attachment, Ser102, is found to be part of a catalytic triad involving His234 and Glu210 (Figure 7B). In other $\alpha / \beta$ hydrolases, the Ser nucleophile is located at the apex of a tight $\beta$-to- $\alpha$ transition, termed the nucleophile elbow, that is facilitated by a strictly conserved consensus $\mathrm{Sm}-\mathrm{X}-\mathrm{Nu}-\mathrm{X}-\mathrm{Sm}$ 

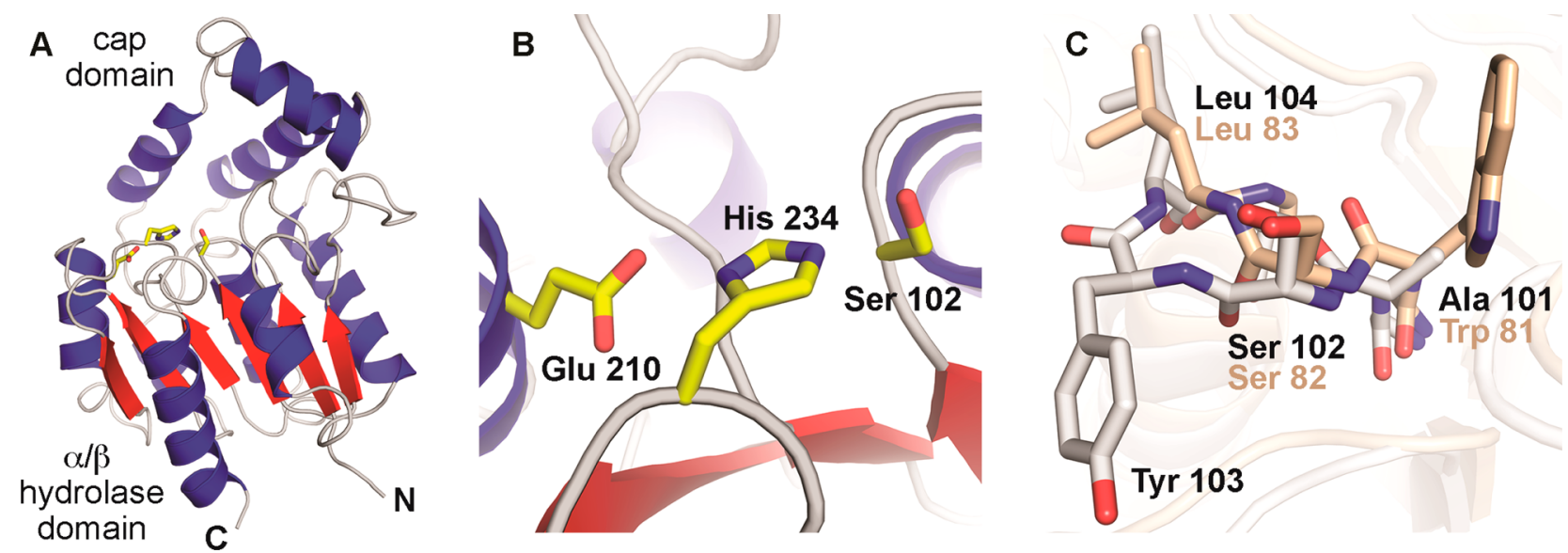

Figure 7. (A) Ribbon diagram of the overall structure of NosK, featuring the core $\alpha / \beta$ hydrolase domain and the cap domain. The catalytic triad is shown in yellow stick format. (B) NosK Ser-His-Glu catalytic triad. (C) Overlay of the nucleophile elbow in BioH (PDB accession code 4ETW) ${ }^{28}$ $(\tan )$ and NosK (white) showing insertion of Tyr103 near the Ser102 nucleophile.

$\left(\mathrm{X}=\right.$ any amino acid, Sm $=$ Gly/Ala) motif. $^{24}$ In NosK, Ser102 is found instead in a $\mathrm{GAS}_{102} \mathrm{YLG}$ sequence, which deviates from the consensus via insertion of an additional hydrophobic residue following the nucleophile. The insertion extends the turn by one residue, allowing the neighboring Tyr side chain to partially occlude the Ser nucleophile (Figure 7C). This modification to the consensus sequence is also found in the $\mathrm{N}$-terminal region of Nocardia NocK and may be linked to the proposed acyltransferase function of the two enzymes. Insertion of a bulky side chain could promote retention of the acylenzyme intermediate via local protection from solvent to prevent unwanted attack by water molecules. The insertion is also found in several of the closest homologues to NosK identified in a BLAST search, many of which are uncharacterized but currently annotated as hydrolases.

In addition to the $\alpha / \beta$ hydrolase domain, NosK contains an ancillary cap domain composed of three short alpha helices inserted between $\beta 4$ and $\alpha 4$ in the core hydrolase fold (Figure $8 \mathrm{~A}$, right panel). Although the general domain architecture is typical of the haloalkane dehalogenase (HAD) subfamily, ${ }^{25}$ the cap motif in NosK is particularly small owing to truncation of the cap secondary structures. The cap region borders the NosK active site, generating a wide shallow groove, presumably for substrate interaction, that is $\sim 25 \AA$ long and $17 \AA$ wide. The arrangement yields a highly exposed catalytic triad when compared to prototypical HAD-type hydrolases with larger cap structures (Figure $8 \mathrm{~A}-\mathrm{C}$, left panels). ${ }^{26}$ The open state may facilitate interaction with protein/peptide-based substrates such as the MIA-NosJ ACP complex and the thiopeptide acceptor. Query of the DALI structural comparison database reveals a similar abbreviated cap domain in human drug metabolism enzyme valacyclovirase, an amino acid esterase with broad substrate specificity. ${ }^{27}$ In that system, the open active site structure is functionally relevant and responsible for the ability to bind a diverse spectrum of target molecules. Despite the small NosK-like cap structure, the catalytic triad in valacyclovirase remains less solvent exposed than the NosK active site. As in most other HAD-type hydrolases, valacyclovirase contributes an Asp as the third acidic component of the catalytic triad from a loop structure that blocks the active site distal to the cap domain. NosK instead uses a longer Glu side chain contributed by a helix within the core fold (Figure S4). The alternative mechanism of catalytic
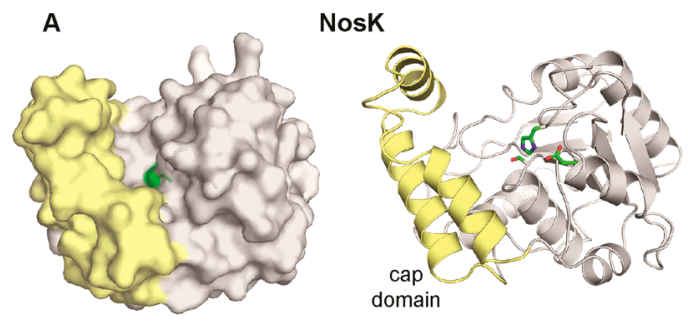

B Valacyclovirase
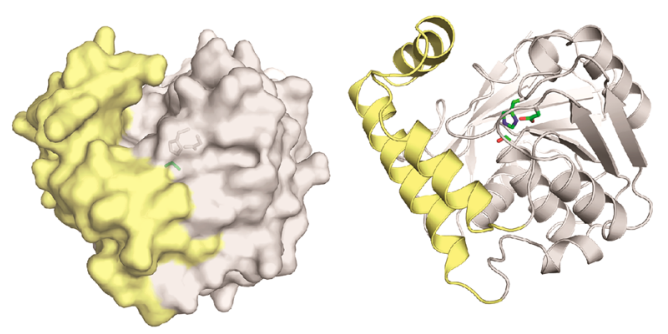

C
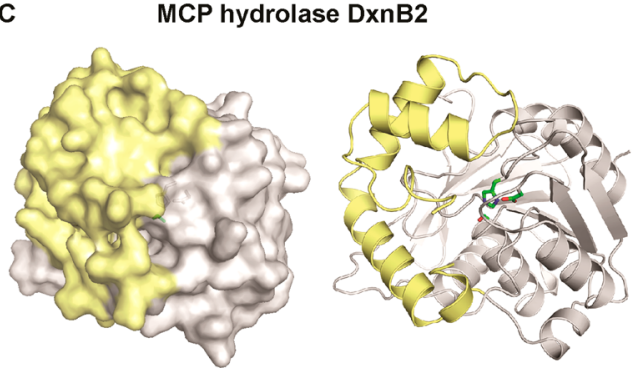

Figure 8. Space-filling and cartoon models of NosK (A) and two structurally similar proteins, MCP hydrolase (PDB accession code $4 \mathrm{LXG})^{26}(\mathrm{~B})$ and valacyclovirase (PDB accession code $\left.2 \mathrm{OCG}\right)^{27}(\mathrm{C})$. Cap domain shown in yellow and catalytic serine (left) or triad (right) shown in green.

triad formation allows open access to the active site from two different directions in NosK.

The NosK cap domain itself may be directly involved in interaction with NosJ, a mode of complex formation with precedent in the biotin biosynthesis pathway (Figure 9A). ${ }^{28}$ 


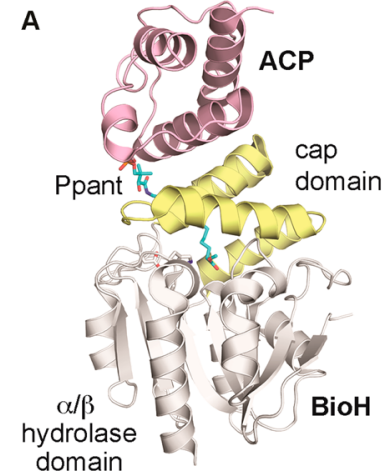

B

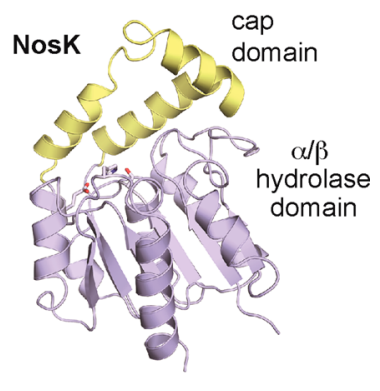

Figure 9. Structures of ACP-BioH (A) (PDB accession code 4ETW $)^{28}$ and NosK (B). In BioH, the cap domain has been shown to mediate the binding of ACP tethered to a phosphopantetheine-fatty acid substrate (Ppant, aqua).

$\mathrm{BioH}$ is a HAD-type $\alpha / \beta$ hydrolase that cleaves the terminal methyl ester of an 8-carbon fatty acid substrate attached to an ACP-phosphopantetheine carrier. BioH harbors a typical large cap domain that occludes the nucleophilic Ser. The ACP binding partner sits on top of the cap domain, threading the linear fatty acid tail through a substrate channel to the active site. The structure suggests a model for NosJ interaction with the smaller NosK cap domain in which the open active site cavity may be better suited to accommodate the bulkier MIA appendage. Analysis of the NosK electrostatic surface potential in the vicinity of the Ser 102 nucleophile indicates the active site cavity is largely hydrophobic but flanked by regions of positive and negative charge (Figure S5). The charged regions could be important for directing the MIA-NosJ donor and peptide acceptor to different parts of the active site.

\section{DISCUSSION}

The thiopeptide natural products have recently received a tremendous amount of attention due to their potent in vitro activities against a variety of Gram-positive pathogens of significant clinical relevance. Their practical use in humans has been hampered, however, by poor solubility and poor pharmacokinetic properties, mandating generation of more practical analogs of these natural products by synthetic, biosynthetic, and semisynthetic methods. ${ }^{2,3,5}$ Pioneering studies by Liu and colleagues led to the identification of the operon for nosiheptide biosynthesis and the discovery that the natural product is derived from a ribosomally synthesized peptide. ${ }^{8}$ In the model put forth by the Liu laboratory (Figure 2b), NosK functions to transfer an MIA or a DMIA moiety from a CoA- or an AMP-linked precursor to Cys- 8 of the structural peptide. In the event that MIA is transferred rather than DMIA, then NosN would methylate this species to give DMIA. Next, the C4 methyl moiety of the DMIA moiety was suggested to be hydroxylated by one of two $\mathrm{P}_{450}$ enzymes. Lastly, Glu- 6 of the structural peptide was postulated to be adenylated by NosI, allowing the C4 hydroxyl group of DMIA to displace the adenylate and form the ester linkage of the side-ring system.

Our own studies indicate a different route for attachment of the indolic acid moiety to the thiopeptide framework of nosiheptide. We functionally assigned NosJ, for the first time, as an ACP that plays an integral role in DMIA synthesis and transfer, and characterized NosI as the protein that activates MIA for transfer to the phosphopantetheine prosthetic group of NosJ. Lastly, a conserved seryl residue (Ser102) on NosK, which anchors a Ser-His-Glu catalytic triad, accepts the MIA group from ACP and presumably transfers it to the thiopeptide framework at some stage of its maturation. The structure of NosK is consistent with this postulated role. Its active site contains a shallow groove that is formed at the interface of the $\alpha / \beta$ hydrolase and cap domains. The cap domain most likely participates in the binding of NosJ to NosK, as is observed in the structure of the similar enzyme $\mathrm{BioH}$. The rectangular groove shape in NosK may also be particularly well-suited to interact with a linear thiopeptide in the second half of the acyltransfer reaction.

We have some insight into the timing of DMIA incorporation from recent studies of nosiheptide biosynthesis in $\mathrm{S}$. actuosus, in which nos $O$ was deleted in a strain of the native producer bacterium that had several copies of the gene encoding NosM present in trans. This approach led to the identification and characterization of a low-yield off-pathway intermediate that lacked the six-membered heterocycle in nosiheptide, but which contained fully installed thiazoles and dehydro-amino acids. As expected, the large macrocycle was not formed, given that the six-membered heterocycle is involved in the connections that form the macrocycle; however, the smaller side ring system, in which Glu-6 and Cys- 8 are bridged by the DMIA moiety, was present. No other posttranslational modifications were observed, suggesting that they are not required for transfer of MIA or DMIA to the thiopeptide framework or for formation of the side ring system. $^{29}$ Moreover, previous studies indicate that transfer of the MIA/DMIA moiety to the thiopeptide framework is

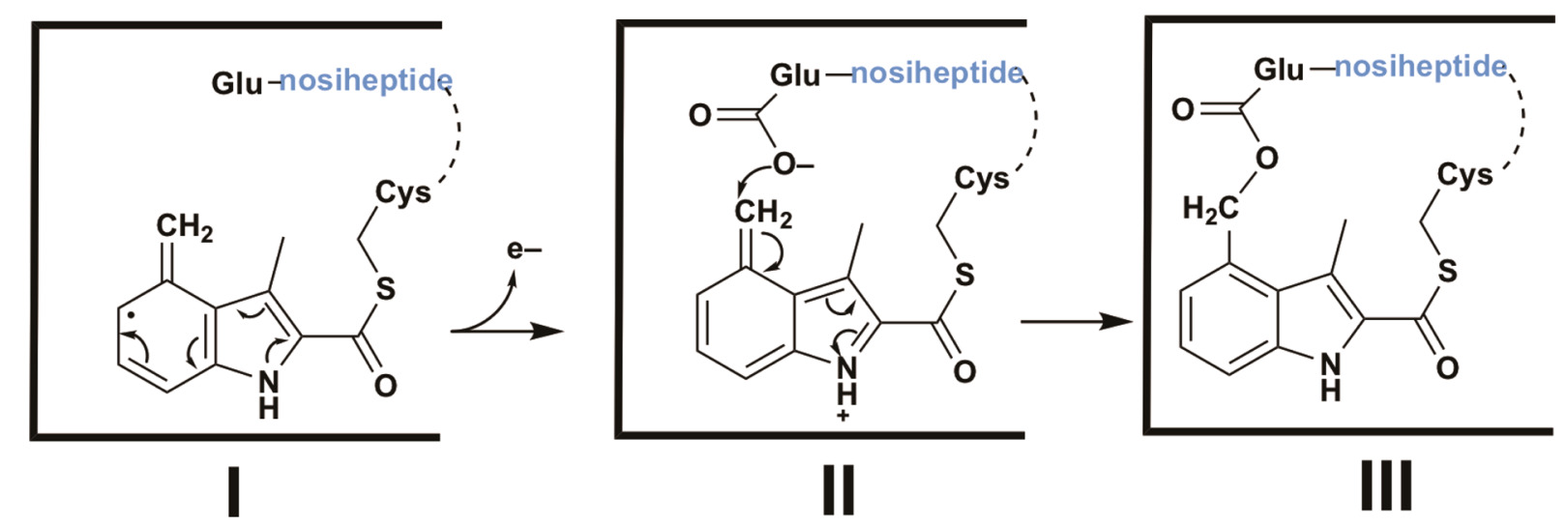

Figure 10. Postulated mechanism for NosN-catalyzed formation of side-ring system. 
necessary for formation of the core macrocycle and that NosI plays a key role in this process. ${ }^{8,30}$ Together, these results and observations suggest that the NosK-mediated transfer of the MIA/DMIA moiety to the thiopeptide framework occurs before formation of the six-membered heterocycle: either directly on NosM, on NosM after thiazole formation, or on NosM both after thiazole formation and after formation of dehydro-amino acids. We posit that NosN acts subsequently, catalyzing both the transfer of a $\mathrm{C} 1$ unit to $\mathrm{C} 4$ of MIA and the formation of the side ring.

Very recent studies from the Zhang group have shed some light on the mechanism of $\operatorname{NosN}{ }^{31}$ which is a Class C RS methylase, and is therefore expected to bind two molecules of SAM simultaneously to effect its reaction. ${ }^{15,16}$ The authors found that one SAM molecule is used to generate a $5^{\prime}$-dA t that is used to abstract a hydrogen atom from what was originally hypothesized to be the methyl moiety of the second SAM molecule. Unexpectedly, the authors also found that the second SAM molecule is first converted into methylthioadenosine (MTA) before hydrogen-atom abstraction takes place from the methyl moiety of MTA. They postulated the formation of a key species containing a delocalized electron (Figure 10, I) that is formed upon addition of a 5 '-methylthioadenosine- 5 '-methylthio radical to C4 of MIA and subsequent elimination of $5^{\prime}$ thioadenosine. This intermediate is postulated to rearrange to the methylated product upon gain of an electron and a proton. Given that there are no additional $\mathrm{P}_{450}$-like enzymes encoded by genes in the nos operon, needed to hydroxylate the $\mathrm{C} 4$ methyl moiety of the DMIA group according to the pathway shown in Figure 2, as well as our finding that NosI activates the carboxyl group of MIA, we suggest that NosN catalyzes both formation of the intermediate $I$ and subsequent formation of the ester linkage between Glu- 6 of the thiopeptide and C4 of the DMIA moiety. This reaction could arise by loss of an electron from intermediate I to generate the electrophile II. Finally, attack of the carboxyl moiety of Glu-6 onto the exocyclic methylene of II completes formation of the side ring system.

\section{EXPERIMENTAL PROCEDURES}

Materials. All DNA-modifying enzymes and reagents used were purchased from New England Biolabs. DNA isolation kits were purchased from Machery-Nagel. The nosI, nosJ, and nosK genes, optimized for expression in E. coli, were purchased from ThermoFisher Scientific. PfuTurbo DNA polymerase $\mathrm{AD}$ was purchased from Agilent Technologies Inc. Sequencing grade trypsin was purchased from Promega Corporation. Primers were purchased from Integrated DNA Technologies. Deoxynucleotides were purchased from Denville Scientific Corporation. The expression vectors, pET-26b and pET28a, were purchased from EMD Millipore. N-(2-hydroxyethyl)piperizine- $N^{\prime}$-(2-ethanesulfonic acid) (HEPES) was purchased from Fisher Scientific. Imidazole, trifluoroacetic acid (TFA), and 2-(Nmorpholino)ethanesulfonic acid hydrate (MES) were purchased from J. T. Baker Chemical Co. Potassium chloride and glycerol were purchased from EMD Chemicals. 2-Mercaptoethanol and phenylmethanesulfonyl fluoride (PMSF) were purchased from SigmaAldrich. Isopropyl $\beta$-D-1-thiogalactopyranoside (IPTG) and dithiothreitol (DTT) were purchased from Gold Biotechnology. ATP (disodium salt) and coenzyme A (trilithium salt) were purchased from Calbiochem. 3-Methyl indolic acid (MIA) was purchased from Matrix Scientific. Talon metal affinity resin was acquired from Clontech Laboratories Inc., and DE-52 anion-exchange resin was from GE Lifesciences. All other chemicals and materials were of the highest grade available.
General Methods. DNA sequencing was carried out at the Pennsylvania State University Genomic Core facility. UV-visible spectra were recorded on a Cary 50 spectrometer from Varian (Walnut Creek, CA) using the WinUV software package to direct the instrument and manipulate the data. High-performance liquid chromatography (HPLC) was conducted on an Agilent 1100 Series system coupled with an Agilent 1100 Series variable wavelength detector and quaternary pump. Polymerase chain reactions (PCR) were performed using a robocylcer gradient 40 thermal cycler from Stratagene.

Cloning of the nosl Gene into pET-28a. The gene encoding nosI was codon-optimized for expression in E. coli and was delivered as a construct in plasmid pMK-RQ. The gene contained two restriction sites, NdeI ( $5^{\prime}$ end) and EcoRI ( $3^{\prime}$ end), and was cloned into the same restriction sites of a pET-28a vector. The nosI gene was expressed as a fusion protein with an $\mathrm{N}$-terminal hexahistidine $\left(\mathrm{His}_{6}\right)$ tag. The codon-optimized gene sequence of nosI, with the NdeI and EcoRI restriction sites indicated in bold type, is provided in the Supporting Information.

Cloning of the nosJ Gene into pET-26b. The gene encoding nos J was codon-optimized for expression in E. coli and was delivered as a construct in plasmid pMA-T. The gene contained two restriction sites, NdeI ( $5^{\prime}$ end) and EcoRI ( $3^{\prime}$ end), with a stop codon just before the EcoRI site. The gene was excised by digestion with $N d e$ I and EcoRI and cloned into a pET-26b vector that was digested with the same two enzymes. The codon-optimized gene sequence of nosJ, with the NdeI and EcoRI restriction sites indicated in bold type, is provided in the Supporting Information.

Cloning of the nosK Gene into pET-28a. The gene encoding $n o s K$ was codon-optimized for expression in E. coli and was delivered as a construct in plasmid pMA-T. The gene contained two restriction sites, $N d e I$ ( $5^{\prime}$ end) and EcoRI ( $3^{\prime}$ end), and was cloned into the same restriction sites of a pET-28a vector. The listed primers were used to introduce a stop codon at amino acid position 271 . The nosK gene was expressed as a fusion protein with an $\mathrm{N}$-terminal hexahistidine tag. The codon-optimized gene sequence of nosK, with the NdeI and EcoRI restriction sites indicated in bold type, is provided in the Supporting Information.

Construction of the NosK Ser102Ala Variant. The gene encoding the Ser102Ala variant was constructed by the polymerase chain reaction. The reaction contained $200 \mathrm{ng}$ of template, $0.4 \mu \mathrm{M}$ forward primer (5'-GGTCCGGGTCGTCTGATTGGTGCAGCGTATCTGGGTGGTCCGCTGGC), $0.4 \mu \mathrm{M}$ reverse primer (5'GCCAGCGGACCACCCAGATACGCTGCACCAATCAGACGACCCGGACC-3'), $250 \mu \mathrm{M}$ each dNTP, $1 \times$ PfuTurbo DNA polymerase buffer, and 2.5 U of PfuTurbo DNA polymerase AD in a total of $50 \mu \mathrm{L}$. The reaction was heated at $95{ }^{\circ} \mathrm{C}$ for $5 \mathrm{~min}$ to denature the template. Next, 16 cycles of denaturation, annealing, and extension were performed at $95{ }^{\circ} \mathrm{C}$ for $1 \mathrm{~min}, 55^{\circ} \mathrm{C}$ for $1.5 \mathrm{~min}$, and $68{ }^{\circ} \mathrm{C}$ for 15 min, respectively. A final extension was performed at $68^{\circ} \mathrm{C}$ for $10 \mathrm{~min}$.

Overproduction and Purification of Nosl. E. coli BL-21 (DE3) was transformed with plasmids encoding NosI. An LB media starter culture was inoculated with a single colony and incubated overnight $\left(250 \mathrm{rpm}\right.$ at $\left.37{ }^{\circ} \mathrm{C}\right)$. Several shake flasks of LB media were then inoculated with the overnight starter culture to initiate growth (180 $\mathrm{rpm}$ at $37^{\circ} \mathrm{C}$ ). Gene expression was induced with $0.5 \mathrm{mM}$ IPTG at an $\mathrm{OD}_{600}$ of $\sim 0.6$, and the flasks were subsequently placed in an ice bath for $1 \mathrm{~h}$. Once cooled, the cultures were incubated overnight (approximately $18 \mathrm{~h}$ ) at $18{ }^{\circ} \mathrm{C}$ with shaking at $180 \mathrm{rpm}$. The cells were harvested $(\sim 30 \mathrm{~g})$, flash frozen in liquid nitrogen, and stored $-80{ }^{\circ} \mathrm{C}$.

For purification, $30 \mathrm{~g}$ of cell paste was resuspended in $150 \mathrm{~mL}$ of lysis buffer (50 mM HEPES, pH 7.5, $300 \mathrm{mM} \mathrm{KCl,} \mathrm{10 \%} \mathrm{glycerol,} 5$ $\mathrm{mM}$ ATP, and $10 \mathrm{mM}$ BME) containing PMSF ( $1 \mathrm{mM})$, DNase 1 $\left(100 \mu \mathrm{g} \mathrm{mL}^{-1}\right)$, and lysozyme $\left(1 \mathrm{mg} \mathrm{mL}^{-1}\right)$. Once the cells were resuspended, they were placed in an ice-bath and subjected to 6 sonication bursts ( $40 \%$ output) of $45 \mathrm{~s}$ with $8 \mathrm{~min}$ pauses between bursts to allow the temperature to re-equilibrate. The lysate was then centrifuged for $1 \mathrm{~h}$ at $50,000 \mathrm{~g}$ at $4{ }^{\circ} \mathrm{C}$. The resulting supernatant was loaded onto a Talon cobalt resin column already equilibrated with 100 
$\mathrm{mL}$ of lysis buffer. The loaded column was washed twice with $100 \mathrm{~mL}$ of lysis buffer before eluting it with $50 \mathrm{~mL}$ of elution buffer $(50 \mathrm{mM}$ HEPES, $\mathrm{pH} 7.5,300 \mathrm{mM} \mathrm{KCl}, 250 \mathrm{mM}$ imidazole, $10 \%$ glycerol, 1 $\mathrm{mM}$ ATP, and $10 \mathrm{mM} \mathrm{BME}$ ). Two $20 \mathrm{~mL}$ fractions were concentrated using an Amicon Ultra centrifugal filter unit (Millipore; Billerica, MA) with a $10-\mathrm{kDa}$ molecular weight cutoff membrane. The protein was purified further by passing it over a 16/60 S-200 column equilibrated in $300 \mathrm{mM} \mathrm{KCl}, 50 \mathrm{mM}$ HEPES, $\mathrm{pH}$ 7.5, $1 \mathrm{mM}$ ATP, $1 \mathrm{mM}$ DTT, and $20 \%$ glycerol. The protein was then concentrated in the same manner as described above. The concentration of protein was estimated by the Bradford assay. ${ }^{32}$ The protein was flash frozen in microcentrifuge tubes and stored at $-80{ }^{\circ} \mathrm{C}$. The total yield is $\sim 15 \mathrm{mg}$ from $30 \mathrm{~g}$ of frozen cell paste.

Overproduction and Purification of NosJ. Plasmids encoding NosJ were transformed into BL-21 (DE3). An LB media starter culture was then inoculated with a single colony and incubated overnight with shaking $(250 \mathrm{rpm})$ at $37^{\circ} \mathrm{C}$. Several $6 \mathrm{~L}$ shake flasks of LB media were then inoculated with the overnight starter culture and agitated at 180 $\mathrm{rpm}$ and $37^{\circ} \mathrm{C}$. Gene expression was induced with $1 \mathrm{mM}$ IPTG at an $\mathrm{OD}_{600}$ of $\sim 0.6$, and the flasks were subsequently placed in an ice bath for $1 \mathrm{~h}$. Once cooled, the cultures were incubated overnight (approximately $18 \mathrm{~h}$ ) at $18{ }^{\circ} \mathrm{C}$ with shaking $(180 \mathrm{rpm})$. The cells were harvested ( $\sim 30 \mathrm{~g})$, flash frozen in liquid nitrogen, and stored in a liquid nitrogen dewar until purification.

For purification, $30 \mathrm{~g}$ of cell paste was resuspended in $150 \mathrm{~mL}$ of lysis buffer (50 mM Tris- $\mathrm{HCl}$, pH 8.4) containing DNase1 (100 $\mu \mathrm{g}$ $\mathrm{mL}^{-1}$ ) and lysozyme $\left(1 \mathrm{mg} \mathrm{mL}^{-1}\right)$. Once resuspended, the mixture was placed in an ice bath and sonicated (40\% output) for $45 \mathrm{~s}$ with 7 min pauses between bursts, for a total sonication time of $6 \mathrm{~min}$. The lysate was then centrifuged at $35,000 \mathrm{~g}$ for $1 \mathrm{~h}$ at $4{ }^{\circ} \mathrm{C}$. The final supernatant was then diluted with 1 volume of $50 \mathrm{mM} \mathrm{MES,} \mathrm{pH}$ 6.1, and then loaded onto a DE-52 anion-exchange column equilibrated in $50 \mathrm{mM}$ MES buffer, $\mathrm{pH}$ 6.1. Once loaded, the column was washed with $1 \mathrm{~L}$ of $50 \mathrm{mM}$ MES, $\mathrm{pH}$ 6.1, and the protein was eluted with a linear $1 \mathrm{~L}$ gradient of 0 to $0.50 \mathrm{M} \mathrm{KCl}$ in $50 \mathrm{mM} \mathrm{MES,} \mathrm{pH} 6.1$. Fractions were analyzed by sodium dodecyl sulfate-polyacrylamide gel electrophoresis (SDS-PAGE), and those containing significant amounts of NosJ (350 mL total volume) were pooled and concentrated in an Amicon stirred cell with a 3-kDa molecular weight cutoff membrane. The concentrated protein was further purified on a HiPrep 26/60 S-200 column equilibrated in 25 mM HEPES, pH 7.5, $10 \%$ glycerol, and $300 \mathrm{mM} \mathrm{KCl}$. The protein was concentrated using an ultracentrifugal filter, flash frozen in liquid nitrogen, and stored in a liquid nitrogen dewar. The final concentration was determined using an extinction coefficient of $12490 \mathrm{~L} \mathrm{~mol}^{-1} \mathrm{~cm}^{-1} \mathrm{~mol}$ at $280 \mathrm{~nm}$, which was determined from the sequence of NosJ using the ProtParam tool from the ExPASy Proteomics Resource Portal (http://web.expasy.org/ protparam/). The final yield was $\sim 60 \mathrm{mg}$ from $30 \mathrm{~g}$ of cell paste.

Overproduction and Purification of WT NosK and the NosK Ser102Ala Variant. Plasmids encoding WT NosK or the NosK Ser102Ala variant were transformed into E. coli BL-21 (DE3). An LB media starter culture was then inoculated with a single colony and incubated overnight at $37{ }^{\circ} \mathrm{C}$ with shaking at $250 \mathrm{rpm}$. Several shake flasks of LB media were then inoculated with the overnight starter culture to initiate growth $\left(180 \mathrm{rpm}\right.$ at $\left.37^{\circ} \mathrm{C}\right)$. Gene expression was induced with $1 \mathrm{mM}$ IPTG at an $\mathrm{OD}_{600}$ of $\sim 0.6$, and the flasks were immediately placed in an ice bath for $1 \mathrm{~h}$. Once cooled, the cultures were incubated overnight for $18 \mathrm{~h}$ at $18{ }^{\circ} \mathrm{C}$ with shaking at $180 \mathrm{rpm}$. The cells were harvested $(\sim 20 \mathrm{~g})$, flash-frozen in liquid nitrogen, and stored at $-80{ }^{\circ} \mathrm{C}$.

For purification, $20 \mathrm{~g}$ of frozen cell paste was resuspended in 150 $\mathrm{mL}$ of lysis buffer (50 mM HEPES, pH 7.5, $300 \mathrm{mM} \mathrm{KCl,} \mathrm{10 \%} \mathrm{(v/v)}$ glycerol, and $10 \mathrm{mM} \mathrm{BME})$ containing PMSF $(1 \mathrm{mM})$, DNase1 (100 $\left.\mu \mathrm{g} \mathrm{mL} L^{-1}\right)$, and lysozyme $\left(1 \mathrm{mg} \mathrm{mL}{ }^{-1}\right)$. Resuspended cells were incubated on ice and subjected to six sonication bursts on a QSonica instrument (40\% output) for $45 \mathrm{~s}$ each with $8 \mathrm{~min}$ intermittent pauses. The lysate was then centrifuged for $1 \mathrm{~h}$ at $50,000 \mathrm{~g}$ at $4{ }^{\circ} \mathrm{C}$. The supernatant was then loaded onto Talon $\mathrm{Co}\left(2^{+}\right)$resin equilibrated in the lysis buffer. The resin was washed twice with $100 \mathrm{~mL}$ of the lysis buffer prior to elution of His-tagged NosK with $50 \mathrm{~mL}$ of elution buffer (50 mM HEPES, pH 7.5, $30 \mathrm{mM} \mathrm{KCl,} 250 \mathrm{mM}$ imidazole, 10\% (v/v) glycerol, and $10 \mathrm{mM} \mathrm{BME}$ ). The pooled eluate was concentrated by ultracentrifugation using an Amicon Ultra centrifugal filter unit with a $10-\mathrm{kDa}$ molecular weight cutoff membrane. The protein was purified further by passage over a HiPrep 16/60 S200 column equilibrated in $300 \mathrm{mM} \mathrm{KCl}, 50 \mathrm{mM}$ HEPES, $\mathrm{pH}$ 7.5, $1 \mathrm{mM}$ DTT, and $10 \%(\mathrm{v} / \mathrm{v})$ glycerol. The protein was then concentrated in this buffer as described above and stored in liquid nitrogen. The final concentration of NosK was estimated by UV-vis spectroscopy using an extinction coefficient of $29450 \mathrm{~L} \mathrm{~mol}^{-1} \mathrm{~cm}^{-1}$ at $280 \mathrm{~nm}$ obtained using the ProtParam tool of the ExPASy proteomics resource portal (http://web.expasy.org/protparam/). The final yield was $\sim 100 \mathrm{mg}$ of protein per $20 \mathrm{~g}$ of cell paste.

Nosl Activity Determinations. Reaction mixtures contained 25 $\mathrm{mM}$ HEPES, $\mathrm{pH} 7.5,1 \mathrm{mM}$ ATP, $1 \mathrm{mM}$ MIA, and varying concentrations of NosI $(2,4$, and $8 \mu \mathrm{M})$, and were performed in triplicate. All reaction components except MIA were mixed and then equilibrated in an ice-water bath in which the reactions were conducted. Reactions were initiated by the addition of MIA, and at designated times, $10 \mu \mathrm{L}$ aliquots were removed and added to $10 \mathrm{~mL}$ of a solution containing $100 \mu \mathrm{M}$ tryptophan (internal standard) and 50 $\mathrm{mM} \mathrm{H}_{2} \mathrm{SO}_{4}$ to quench the reaction. Products were then analyzed by HPLC with detection by mass spectrometry (LC-MS).

LC-MS Method. HPLC with detection by positive-mode electrospray-ionization $\left(\mathrm{ESI}^{+}\right)$mass spectrometry was conducted on an Agilent Technologies 1260 system coupled to an Agilent Technologies 6460 triple-quad mass spectrometer. The associated MassHunter software package was used to operate the system and to collect and analyze the data. Each quenched reaction was injected onto an Agilent Technologies Zorbax Rapid Resolution XBD-C18 column (4.6 mm $\times$ $50 \mathrm{~mm}, 1.8 \mu \mathrm{M}$ particle size). The column was first equilibrated in $95 \%$ solvent A $(0.1 \%$ formic acid) and 5\% solvent B (100\% acetonitrile). From 0 to $2 \mathrm{~min}$, a linear gradient from $5 \%$ to $60 \%$ solvent B was applied. From 2 to $2.5 \mathrm{~min}$, the gradient was increased linearly from $60 \%$ to $100 \%$ solvent B. From 2.5 to $4.5 \mathrm{~min}$, the gradient was decreased linearly to $5 \%$ solvent $\mathrm{B}$ and was then held constant for an additional $5 \mathrm{~min}$. A constant flow rate of $0.7 \mathrm{~mL} / \mathrm{min}$ was used throughout the method. MIA-AMP and tryptophan were detected using the single-ion monitoring (SIM) mode. The set fragmentor voltages for MIA-AMP and for tryptophan were 135 and $130 \mathrm{~V}$, respectively.

Analysis of the Reaction Containing Nosl, NosJ, and NosK. The basic reaction mixture consisted of $25 \mathrm{mM}$ HEPES, pH 7.5, $1 \mathrm{mM}$ CoA, and $400 \mu \mathrm{M}$ NosJ in a total volume of $40 \mu \mathrm{L}$. For formation of holo NosJ, 36.7 $\mu \mathrm{M} \mathrm{Ec} \mathrm{holo} \mathrm{ACP} \mathrm{synthase,} \mathrm{prepared} \mathrm{as} \mathrm{previously}$ described, ${ }^{19,20}$ was included. For formation of MIA-holo NosJ, $20 \mu \mathrm{M}$ NosI, $2 \mathrm{mM}$ ATP, $2 \mathrm{mM}$ MIA, $100 \mathrm{mM} \mathrm{MgCl}$, and $36.7 \mu \mathrm{M} E c$ holo ACP synthase was included. Control reactions had either ATP, MIA, or NosI omitted. Assays were quenched with 0.2\% TFA, pH 2.4, after $2 \mathrm{~h}$ at room temperature, and then analyzed by HPLC.

Samples were analyzed using the Agilent 1100 series HPLC ChemStation software. A Zorbax 300 stable bond C18 $5 \mu \mathrm{m} 4.6 \mathrm{~mm} \times$ $250 \mathrm{~mm}$ column was used with three different solvents at a flow rate of $1.3 \mathrm{~mL} / \mathrm{min}$ : solvent $\mathrm{A}, 0.2 \% \mathrm{TFA}, \mathrm{pH} 2.4$; solvent $\mathrm{B}$, acetonitrile; and solvent $\mathrm{C}$, methanol. The column was equilibrated in $5 \%$ solvent $\mathrm{B}$ and $95 \%$ solvent $\mathrm{A}$, which was maintained for $30 \mathrm{~s}$ after injection. From 30 $\mathrm{s}$ to $4 \mathrm{~min}$, solvents $\mathrm{B}$ and $\mathrm{C}$ were increased to $39 \%$ and $9 \%$, respectively. From 4 to $12 \mathrm{~min}$, solvent $\mathrm{C}$ was increased to $11.8 \%$, while solvent B was held constant at $39 \%$. From 12 to $22 \mathrm{~min}$, solvent $\mathrm{C}$ was increased to $50 \%$, while solvent B was held constant at $39 \%$. From 22 to 25 min, solvents B and C were held constant at $39 \%$ and $50 \%$, respectively. From 25 to $27 \mathrm{~min}$, solvent $\mathrm{B}$ was increased to $100 \%$. From 27 to $28 \mathrm{~min}$, solvent B was held constant at $100 \%$. From 28 to $29.5 \mathrm{~min}$, solvent B was decreased to $5 \%$. From 29.5 to $32 \mathrm{~min}$, solvent B was held constant at 5\%.

MS Analysis of Nosl, NosJ, and NosK Reactions. The complete reaction (Figure 3, panel 4) contained the following in a final volume of $400 \mu \mathrm{L}: 300 \mu \mathrm{M}$ NosJ, $18 \mu \mathrm{M}$ holo ACP synthase, $25 \mu \mathrm{M}$ NosI, 300 $\mu \mathrm{M}$ NosK, $25 \mathrm{mM}$ HEPES, pH 7.5, $500 \mu \mathrm{M}$ CoA, $1 \mathrm{mM}$ ATP, $1 \mathrm{mM}$ MIA, and $100 \mathrm{mM} \mathrm{MgCl}_{2}$. For some reactions, various components of 
the complete reaction mixture were omitted as indicated in the text and legend for Figure 3. The reaction corresponding to panel 1 contained $300 \mu \mathrm{M}$ NosJ, $25 \mathrm{mM}$ HEPES, $\mathrm{pH} 7.5,400 \mu \mathrm{M}$ CoA, and $100 \mathrm{mM} \mathrm{MgCl}$. The reaction corresponding to panel 2 contained 300 $\mu \mathrm{M}$ NosJ, $25 \mathrm{mM}$ HEPES, pH 7.5, $1 \mathrm{mM} \mathrm{CoA}, 100 \mathrm{mM} \mathrm{MgCl}_{2}$, and $18 \mu \mathrm{M} E c$ holo ACP synthase. The reaction corresponding to panel 3 contained $300 \mu \mathrm{M}$ NosJ, $20 \mu \mathrm{M}$ NosI, $25 \mathrm{mM}$ HEPES, pH 7.5, 500 $\mu \mathrm{M} \mathrm{CoA}, 100 \mathrm{mM} \mathrm{MgCl}, 1 \mathrm{mM}$ ATP, $1 \mathrm{mM}$ MIA, and $18 \mu \mathrm{M} \mathrm{Ec}$ holo ACP synthase. The reactions were incubated at room temperature for at least $1 \mathrm{~h}$ before being frozen and stored at -80 ${ }^{\circ} \mathrm{C}$ until ready for analysis.

MS analysis was performed on a Waters Q-TOF Premier quadrupole/time-of-flight (TOF) mass spectrometer (Waters Corporation, Micromass Ltd., Manchester, UK). Operation of the mass spectrometer was performed using MassLynx software Version 4.1 (http://www.waters.com). Samples were introduced into the mass spectrometer using a Waters 2695 HPLC system. Separation was performed by gradient elution on a Thermo BioBasic C4, $50 \times 2.1 \mathrm{~mm}$ HPLC column. The mobile phases used were $0.1 \%$ formic acid in deionized water (solvent $\mathrm{A}$ ), and $0.1 \%$ formic acid in acetonitrile (solvent B) at a flow rate of $0.2 \mathrm{~mL} / \mathrm{min}$. The column was equilibrated in $2 \%$ solvent $\mathrm{B}$, which was held constant for $1 \mathrm{~min}$ after sample (15 $\mu \mathrm{L}$ ) injection. From 1.0 to $2.0 \mathrm{~min}$, a linear gradient from $2 \%$ to $95 \%$ solvent B was applied, which was held constant at $95 \%$ solvent B from 2.0 to $15.0 \mathrm{~min}$. From 15.0 to $15.1 \mathrm{~min}$, a linear gradient from $95 \%$ to $2 \%$ solvent B was applied, which was held constant at $2 \%$ solvent B from 15.1 to $20.0 \mathrm{~min}$. Data acquisition was performed during the first $15 \mathrm{~min}$ of the run, whereas the final $5 \mathrm{~min}$ was used for column reequilibration. The nitrogen drying gas temperature was set to $300{ }^{\circ} \mathrm{C}$ at a flow rate of $6 \mathrm{~L} / \mathrm{min}$. The capillary voltage was $2.8 \mathrm{kV}$. The mass spectrometer was set to scan from 500 to $2500 \mathrm{~m} / z$ in positive ion mode, using electrospray ionization.

MS Analysis of Trypsin-Digested NosK. The reaction mixture consisted of $50 \mu \mathrm{M}$ NosJ, $50 \mu \mathrm{M}$ NosI, $500 \mu \mathrm{M}$ NosK, $100 \mathrm{mM}$ $\mathrm{MgCl}_{2}, 2 \mathrm{mM}$ ATP, $2 \mathrm{mM}$ MIA, $25 \mathrm{mM}$ HEPES, pH 7.5, $0.1 \mathrm{mM}$ $\mathrm{CoA}$, and $10 \mu \mathrm{M}$ holo ACP synthase in a total volume of $30 \mu \mathrm{L}$. The reaction was incubated at room temperature for approximately $1 \mathrm{~h}$ and then quenched with $30 \mu \mathrm{L}$ of $2 \times$ SDS-PAGE buffer. A control reaction that lacked NosI was also prepared and treated identically. NosK was separated from other proteins on a $12 \%$ SDS-PAGE gel, and the corresponding band was excised. An in-gel trypsin digestion was performed on the excised band with sequencing-grade lyophilized trypsin and subsequently analyzed at the Penn State Proteomics and Mass Spectrometry Core facility.

Mass spectra of tryptic digests were acquired using the default instrument parameters for the reflector positive-ion detection over the $700-3000 \mathrm{~m} / z$ range, and the method was calibrated with a bovine serum albumin tryptic digest standard (Protea Biosciences). Mass spectra were opened in the Bruker FlexAnalysis, smoothed by Savitzky-Golay filtering $(0.2 \mathrm{~m} / \mathrm{z}, 1$ cycle $)$, and baseline-subtracted using Top-Hat filtering. The mass lists were generated using a SNAP peak detection algorithm with a signal-to-noise threshold set at 6 and using the averagine SNAP average composition. The peak at $\mathrm{m} / \mathrm{z}$ 1581.733 was selected for TOF-TOF analysis to establish the modification position. The resulting $\mathrm{MS}^{2}$ data were processed using the default parameters and loaded into the Bruker Biotools application. The fragment ions were identified based on the best match between the experimental mass spectra and the peak assignments generated by the Sequence Editor within Biotools.

HPLC Analysis of NosK Acylation. The complete reaction contained the following in a total volume of $30 \mu \mathrm{L}: 250 \mu \mathrm{M}$ NosK, 50 $\mu \mathrm{M}$ NosJ, $25 \mu \mathrm{M}$ NosI, $10 \mu \mathrm{M} E c$ holo ACP synthase, $2 \mathrm{mM}$ ATP, 2 $\mathrm{mM}$ MIA, $100 \mu \mathrm{M} \mathrm{CoA}$, and $25 \mathrm{mM}$ HEPES, $\mathrm{pH}$ 7.5. For some reactions, various components of the complete reaction mixture were omitted as indicated in the text and legend for Figure 6. NosK control consisted of $250 \mu \mathrm{M}$ NosK, $100 \mathrm{mM} \mathrm{MgCl}_{2}$, and $25 \mathrm{mM}$ HEPES, $\mathrm{pH}$ 7.5. The control acylated NosK reaction consisted of $250 \mu \mathrm{M}$ NosK, $50 \mu \mathrm{M}$ NosJ, $10 \mu \mathrm{M} E c$ Holo ACP synthase, $2 \mathrm{mM}$ ATP, 2 mM MIA, $100 \mu \mathrm{M}$ CoA, and $25 \mathrm{mM}$ HEPES $\mathrm{pH}$ 7.5. The NosK S102A reaction contained $250 \mu \mathrm{M}$ NosK S102A, $50 \mu \mathrm{M}$ NosJ, $25 \mu \mathrm{M}$ NosI, $10 \mu \mathrm{M}$ Ec
Holo ACP synthase, $2 \mathrm{mM}$ ATP, $2 \mathrm{mM}$ MIA, $100 \mu \mathrm{M}$ CoA, and 25 $\mathrm{mM}$ HEPES $\mathrm{pH}$ 7.5. The reactions were in a total volume of $30 \mu \mathrm{L}$ and were incubated at room temperature for approximately $1 \mathrm{~h}$. Before analysis by HPLC, the reactions were quenched with $0.2 \%$ TFA pH 2.4.

Samples were analyzed using the Agilent 1100 series HPLC ChemStation software. A Zorbax 300 stable bond C18 $5 \mu \mathrm{m} 4.6 \mathrm{~mm} \times$ $250 \mathrm{~mm}$ column was used with two different solvents: solvent $\mathrm{A}, 0.2 \%$ TFA pH 2.4 and solvent $\mathrm{B}$, acetonitrile flowed at $1.4 \mathrm{~mL}$ per minute. The column was equilibrated in $45 \%$ solvent $\mathrm{B}$ and $55 \%$ solvent $\mathrm{A}$, which was maintained for $3 \mathrm{~min}$ after injection. From 3 to $13 \mathrm{~min}$, solvent B was increased to $57 \%$. From 13 to 14 min, solvent B was increased to $100 \%$. From 14 to $16 \mathrm{~min}$, solvent B was held constant at $100 \%$. From 16 to $17 \mathrm{~min}$, solvent B was decreased to $45 \%$. From 17 to $18 \mathrm{~min}$, solvent $\mathrm{B}$ was held constant at $45 \%$.

Crystallization and X-ray Structure Determination of NosK. A concentrated stock solution of NosK, prepared as described above, was diluted to $9 \mathrm{mg} / \mathrm{mL}$ in $10 \mathrm{mM}$ Tris- $\mathrm{HCl}$, $\mathrm{pH}$ 8.4, containing 300 $\mathrm{mM} \mathrm{KCl}$. Clear rod-shaped crystals appeared within 2 to 3 weeks at room temperature by using the hanging drop vapor diffusion method. Trays were prepared by mixing $1 \mu \mathrm{L}$ of protein solution and $1 \mu \mathrm{L}$ of precipitating solution containing $1.6 \mathrm{M}\left(\mathrm{NH}_{4}\right)_{2} \mathrm{SO}_{4}, 0.1 \mathrm{M} \mathrm{NaCl}, 0.1$ $\mathrm{M}$ HEPES, $\mathrm{pH} 7.5$, and equilibrating the drops against a $0.5 \mathrm{M} \mathrm{LiCl}$ well solution. Crystals were removed directly from their drops with rayon loops with no further cryoprotection and flash-frozen in liquid nitrogen.

X-ray diffraction data sets were collected at the Life Sciences Collaborative Access Team (LS-CAT) beamline 21-ID-G at the Advanced Photon Source. Data sets were processed using iMosflm ${ }^{33}$ and phased by molecular replacement using BALBES. ${ }^{34}$ Manual model building with Coot, ${ }^{35}$ using the initial search model S. aureus $\mathrm{MenH}$ (PDB accession code $2 \mathrm{XMZ})^{36}$ as a template, and refinement in PHENIX $^{37}$ and Refmac5 ${ }^{38}$ yielded a final model consisting of residues 28-257, 91 water molecules, and one sulfate anion. Figures were generated using the PyMOL molecular graphics software package (Schrödinger LLC) and electrostatic surface maps were obtained with the APBS software plugin. ${ }^{39}$ Data collection and refinement statistics are shown in Table S3.

\section{ASSOCIATED CONTENT}

\section{Supporting Information}

The Supporting Information is available free of charge on the ACS Publications website at DOI: 10.1021/jacs.7b01497.

Gene sequences for nosI, nos J and nosK, Figures S1-S5, and Tables S1-S3 (PDF)

\section{AUTHOR INFORMATION}

\section{Corresponding Authors}

*akb20@psu.edu

*squire@psu.edu

ORCID

Amie K. Boal: 0000-0002-1234-8472

Squire J. Booker: 0000-0002-7211-5937

\section{Present Address}

†Department of Biochemistry and Department of Physiology \& Biophysics, Albert Einstein College of Medicine, 1300 Morris Park Ave., Forchheimer Building, Bronx, NY 10461

\section{Author Contributions}

The manuscript was written through contributions of all authors, each of whom has given approval to the final version of the manuscript.

Notes

The authors declare no competing financial interest. 


\section{ACKNOWLEDGMENTS}

We thank Drs. Tatiana Laremore and James Miller of the Penn State Proteomics and Mass Spectrometry Core Facility, University Park, PA, for performing mass spectrometric analyses. We also thank Dr. Neela Yennawar of the Huck Institutes of Life Sciences or her help with X-ray structure determination. This research used resources of the Advanced Photon Source, a U.S. Department of Energy Office (DOE) of Science User Facility operated for the DOE Office of Science by Argonne National Laboratory under Contract No. DEAC02-06CH11357. S.J.B. is an investigator of the Howard Hughes Medical Institute. This work was supported by NIH Grants GM-101957, GM 103268, and GM-122595, Penn State funds for undergraduate research, and a grant from the Pennsylvania Department of Health (TSR13/14 SAP 4100062216), all to S.J.B. It was also supported by an NIH K99/R00 Pathway to Independence award to A.K.B. (GM100011), and a Rodney Erickson Discovery Grant for undergraduate research to E.D.B.

\section{REFERENCES}

(1) Benazet, F.; Cartier, M.; Florent, J.; Godard, C.; Jung, G.; Lunel, J.; Mancy, D.; Pascal, C.; Renaut, J.; Tarridec, P.; Theilleux, J.; Tissier, R.; Dubost, M.; Ninet, L. Experientia 1980, 36, 414-416.

(2) Bagley, M. C.; Dale, J. W.; Merritt, E. A.; Xiong, X. Chem. Rev. 2005, 105, 685-714.

(3) Li, C.; Kelly, W. L. Nat. Prod. Rep. 2010, 27, 153-164.

(4) Cundliffe, E.; Thompson, J. Microbiology 1981, 126, 185-192.

(5) Just-Baringo, X.; Albericio, F.; Alvarez, M. Angew. Chem., Int. Ed. 2014, 53, 6602-6616.

(6) Wojtas, K. P.; Riedrich, M.; Lu, J. Y.; Winter, P.; Winkler, T.; Walter, S.; Arndt, H. D. Angew. Chem., Int. Ed. 2016, 55, 9772-9776.

(7) Prange, T.; Ducruix, A.; Pascard, C.; Lunel, J. Nature 1977, 265, 189-190.

(8) Yu, Y.; Duan, L.; Zhang, Q.; Liao, R.; Ding, Y.; Pan, H.; WendtPienkowski, E.; Tang, G.; Shen, B.; Liu, W. ACS Chem. Biol. 2009, 4, 855-864.

(9) Hudson, G. A.; Zhang, Z.; Tietz, J. I.; Mitchell, D. A.; van der Donk, W. A. J. Am. Chem. Soc. 2015, 137, 16012-16015.

(10) Zhang, Z.; Hudson, G. A.; Mahanta, N.; Tietz, J. I.; van der Donk, W. A.; Mitchell, D. A. J. Am. Chem. Soc. 2016, 138, 1551115514.

(11) Yu, Y.; Guo, H.; Zhang, Q.; duan, L.; ding, Y.; Liao, R.; Lei, C.; Shen, B.; Liu, W. J. Am. Chem. Soc. 2010, 132, 16324-16326.

(12) Liu, W.; Xue, Y.; Ma, M.; Wang, S. C.; Liu, N.; Chen, Y. ChemBioChem 2013, 14, 1544-1547.

(13) Zhang, Q.; Li, Y.; Chen, D.; Yu, Y.; Duan, L.; Shen, B.; Liu, W. Nat. Chem. Biol. 2011, 7, 154-160.

(14) Mocek, U.; Knaggs, A. R.; Tsuchiya, R.; Nguyen, T.; Beale, J. M.; Floss, H. G. J. Am. Chem. Soc. 1993, 115, 7557-7568.

(15) Zhang, Q.; van der Donk, W. A.; Liu, W. Acc. Chem. Res. 2012, 45, 555-564.

(16) Bauerle, M. R.; Schwalm, E. L.; Booker, S. J. J. Biol. Chem. 2015, $290,3995-4002$.

(17) Rock, C. O.; Cronan, J. E. J. Biol. Chem. 1979, 254, 9778-9785.

(18) Rock, C. O.; Cronan, J. E. Methods Enzymol. 1981, 71, 341-351.

(19) Nesbitt, N. M.; Baleanu-Gogonea, C.; Cicchillo, R. M.; Goodson, K.; Iwig, D. F.; Broadwater, J. A.; Haas, J. A.; Fox, B. G.; Booker, S. J. Protein Expression Purif. 2005, 39, 269-282.

(20) Warui, D. M.; Pandelia, M. E.; Rajakovich, L. J.; Krebs, C.; Bollinger, J. M., Jr.; Booker, S. J. Biochemistry 2015, 54, 1006-1015.

(21) Rock, C. O.; Garwin, J. L.; Cronan, J. E. Methods Enzymol. 1981, 72, 397-403.

(22) Voet, D.; Voet, J. G.; Pratt, C. W. Fundamentals of Biochemistry: Life at the Molecular Level, Sth ed.; John Wiley \& Sons: Hoboken, NJ, 2016.
(23) Fischbach, M. A.; Walsh, C. T. Chem. Rev. 2006, 106, 34683496.

(24) Nardini, M.; Dijkstra, B. W. Curr. Opin. Struct. Biol. 1999, 9, $732-737$.

(25) Ollis, D. L.; Cheah, E.; Cygler, M.; Dijkstra, B.; Frolow, F.; Franken, S. M.; Harel, M.; Remington, S. J.; Silman, I.; Schrag, J.; Sussman, J. L.; Verschueren, K. H. G.; Goldman, A. Protein Eng., Des. Sel. 1992, 5, 197-211.

(26) Ruzzini, A. C.; Bhowmik, S.; Yam, K. C.; Ghosh, S.; Bolin, J. T.; Eltis, L. D. Biochemistry 2013, 52, 5685-5695.

(27) Lai, L.; Xu, Z.; Zhou, J.; Lee, K. D.; Amidon, G. L. J. Biol. Chem. 2008, 283, 9318-9327.

(28) Agarwal, V.; Lin, S.; Lukk, T.; Nair, S. K.; Cronan, J. E. Proc. Natl. Acad. Sci. U. S. A. 2012, 109, 17406-17411.

(29) Guo, H.; Wang, J.; Li, Y.; Yu, Y.; Zheng, Q.; Wu, J.; Liu, W. Chem. Sci. 2014, 5, 240-246.

(30) Ding, Y.; Yu, Y.; Pan, H.; Guo, H.; Li, Y.; Liu, W. Mol. BioSyst. 2010, 6, 1180-1185.

(31) Ding, W.; Li, Y.; Zhao, J.; Ji, X.; Mo, T.; Qianzhu, H.; Tu, T.; Deng, Z.; Yu, Y.; Chen, F.; Zhang, Q. Angew. Chem., Int. Ed. 2017, 56, 3857.

(32) Bradford, M. Anal. Biochem. 1976, 72, 248-254.

(33) Battye, T. G. G.; Kontogiannis, L.; Johnson, O.; Powell, H. R.; Leslie, A. G. W. Acta Crystallogr., Sect. D: Biol. Crystallogr. 2011, 67, 271-281.

(34) Long, F.; Vagin, A. A.; Young, P.; Murshudov, G. N. Acta Crystallogr., Sect. D: Biol. Crystallogr. 2008, 64, 125-132.

(35) Emsley, P.; Cowtan, K. Acta Crystallogr., Sect. D: Biol. Crystallogr. 2004, 60, 2126-2132.

(36) Dawson, A.; Fyfe, P. K.; Gillet, F.; Hunter, W. N. BMC Struct. Biol. 2011, 11, 19-19.

(37) Adams, P. D.; Afonine, P. V.; Bunkoczi, G.; Chen, V. B.; Davis, I. W.; Echols, N.; Headd, J. J.; Hung, L. W.; Kapral, G. J.; GrosseKunstleve, R. W.; McCoy, A. J.; Moriarty, N. W.; Oeffner, R.; Read, R. J.; Richardson, D. C.; Richardson, J. S.; Terwilliger, T. C.; Zwart, P. H. Acta Crystallogr., Sect. D: Biol. Crystallogr. 2010, 66, 213-221.

(38) Murshudov, G. N.; Vagin, A. A.; Dodson, E. J. Acta Crystallogr., Sect. D: Biol. Crystallogr. 1997, 53, 240-255.

(39) Baker, N. A.; Sept, D.; Joseph, S.; Holst, M. J.; McCammon, J. A. Proc. Natl. Acad. Sci. U. S. A. 2001, 98, 10037-10041. 